\title{
Commercial forest carbon protocol over-credit bias delimited by zero-threshold carbon accounting
}

\author{
Bruno D.V. Marino ${ }^{{ }^{*}}$ and Nahuel Bautista ${ }^{2}$ \\ 1 Planetary Emissions Management Inc., bruno.marino@pem-carbon.com \\ 2 Planetary Emissions Management Inc; nahuel.bautista@pem-carbon.com
}

Abstract: Despite the use of commercial forest carbon protocols (CFCPs) for more than two decades, claiming $\sim 566 \mathrm{MMtCO}_{2} \mathrm{e}$ and a market value of $\sim \mathrm{USD} \$ 15.7$ billion, comparative analysis of CFCP methodology and offset results is limited. In this study, five widely used biometric-based CFCPs were characterized, and common characteristics and differences were identified. CFCP claims of net forest carbon sequestration are compared with results of directly measured $\mathrm{CO}_{2}$ by eddy covariance, a meteorological method integrating gross vertical fluxes of forest and soil carbon, and the only alternative non-biometric source of net forest carbon sequestration data available. We show here that CFCPs share a structural feature delimiting forest carbon values by zero-threshold carbon accounting $\left(\mathrm{gC} \mathrm{m}^{-2} \leq 0\right)$, a pattern opposite to natural emissions of forest $\mathrm{CO}_{2}$ exchange based on direct measurement and a fundamental biological constraint on net forest carbon storage (i.e., soil efflux, ecosystem respiration). Exclusion of forest $\mathrm{CO}_{2}$ sources to the atmosphere precludes net carbon accounting, resulting in unavoidable over-crediting of CFCP offsets. CFCP carbon results are significantly different from global forest $\mathrm{CO}_{2}$ net ecosystem exchange population results (FluxNet2015 $\mathrm{gC} \mathrm{m}^{-2}$ ) at the $95 \%$ to $99.99 \%$ confidence levels, inferring an annual median error of $\sim 247 \%\left(\mathrm{gC} \mathrm{m}^{-2}\right)$, also consistent with over-crediting. Direct $\mathrm{CO}_{2}$ measurement provides an alternative method for commercial forest carbon products, has the potential to harmonize global markets, and catalyze the role of forests in managing climate change through nature-based solutions.

Keywords: ACR, CAR CARB, VERRA, NEE

\section{Introduction}

Commercial forest carbon sequestration protocols, by design, exclude direct measurement of forest $\mathrm{CO}_{2}$ sources and sinks, relying instead on limited forest mensuration, proxy forest data and model growth simulation models [1]-[5] similar to those used in the timber industry [6]. CFCP results for net forest carbon sequestration, if based on incomplete carbon accounting, would be uncertain, calling into question the value of forest carbon offsets and implying that immediate improvement in CFCP methods is needed [7]-[10]. Evaluation of CFCPs is an urgent matter considering 566 million metric tons of claimed forest carbon emission reductions with a value of USD $\sim \$ 15.6$ billion accumulated over the last two decades since the inception of the Kyoto Agreement [11], [12] and the Clean Development Mechanism protocol [13]. In contrast, direct independent measurement of net forest carbon sequestration, an alternative net forest carbon data method addressing the stated objective of CFCPs [14], [15], can also be determined by universally accepted eddy covariance methods resulting in net ecosystem exchange for forest carbon (NEE) [16]. Importantly, NEE integrates the balance between ecosystem gross vertical fluxes of carbon stored through photosynthesis (Gross Primary Production) and that lost via respiration (Reco; comprised of heterotrophic and autotrophic respiration)[17] typically including an inventory of standing biomass and removals $(\mathrm{NEE}=\mathrm{GPP}+\mathrm{Reco})[16]$. NEE interannual 
variability and corresponding Reco versus GPP data for global forests provides population ranges and values reflecting known natural forest carbon dynamics [18]. NEE is the only independent, non-biometric alternative database for comparison with CFCPs [18], [19].

Ecosystem respiration accounts for up to $\sim 82 \%$ of NEE and cannot be excluded when quantifying net forest carbon storage [18], [19]; NEE fills this gap in CFCPs. The absence of positive carbon emission data, as measured directly or inferred by biomass proxies and model simulation, precludes complete carbon accounting for net sequestered forest carbon. Previous results have evaluated the equations and results employed for CFCPs, their statistical differences with global forest data for NEE, and provided a comparison of CFCP features with eddy covariance methods [7], [8]. Moreover, the only site where a CFCP, the California Air Resources Board and the Climate Action Reserve protocols, and the eddy covariance method overlap, has been reported resulting in annual errors of up to 2,256\% relative to eddy covariance data collected over the same project area [7], [8], [20]. An analysis of adherence to regulatory terms and conditions for the CARB-CAR protocol revealed inconsistencies within the carbon offset supply chain, a topic not covered in this study [20]. Studies identifying deficiencies in the CARB-CAR protocol related to additionality and over-crediting based on discrepancies in above ground carbon accounting support the need for improvement in CFCPs [9], [10].

In this study, methodological similarities and differences for the California Air Resources Board (CARB) [1], Climate Action Reserve (CAR) [21], American Carbon Registry (ACR) [22], Clean Development Mechanism (CDM) [13], [23], and the Verified Carbon Standard (VERRA) [24] are described followed by characterization of available forest carbon sequestration project data. NEE global population data [19] are employed in this analysis for comparison with CFCP results (units: $\mathrm{gC} \mathrm{m}^{-2}$ year-1, or day ${ }^{-1}$ ). We summarize differences between methods and results, and statistically analyze the annual and/or daily values and overlapping time series for CFCP and NEE. Results are discussed in the context of the requirements to fully account for forest carbon, specifically the importance of ecosystem respiration, and identifying features of $\mathrm{CFCP}$ data that are not reflective of natural forest carbon cycling. The impacts of incomplete carbon accounting on landholders and carbon markets are discussed, including the benefits of NEE commercialization applied to the Paris Agreement [25], [26] and policy platforms such as the Reducing Emissions from Deforestation and forest Degradation (REDD+)[27]. Improvements for CFCPs and collaboration with forest eddy covariance research are suggested.

\section{Materials and Methods}

\subsection{CFCP Comparative information and site locations}

The features for each commercial forest carbon protocol were obtained from respective websites for the CARB, CAR, ACR, CDM, and VERRA protocols. Sources of eddy covariance results expressed as net ecosystem exchange (NEE, $\mathrm{gC} \mathrm{m}^{-2}$ year $^{-1}\left(\mathrm{y}^{-1}\right)$ or day $\left.\mathrm{y}^{-1}\left(\mathrm{~d}^{-1}\right)\right)$ are also provided. Table 1 summarizes the features of CFCPs and NEE methods; annotations are provided in Appendix 1 (A1.Annotations). Site locations are shown in Figure 1 as excerpted from the sources in Table 1. The CFCPs have 421 projects, covering 1,214 project years. The NEE FluxNet2015 comparative data consisted of 206 sites covering 1,448 project years [19]; daily values for NEE were also acquired from FluxNet2105 (545,323 days)[19] for comparison with VERRA data, the only CFCP that employed a daily carbon data format (6,466 days). Data sources are noted for each individual protocol in Table 1. 


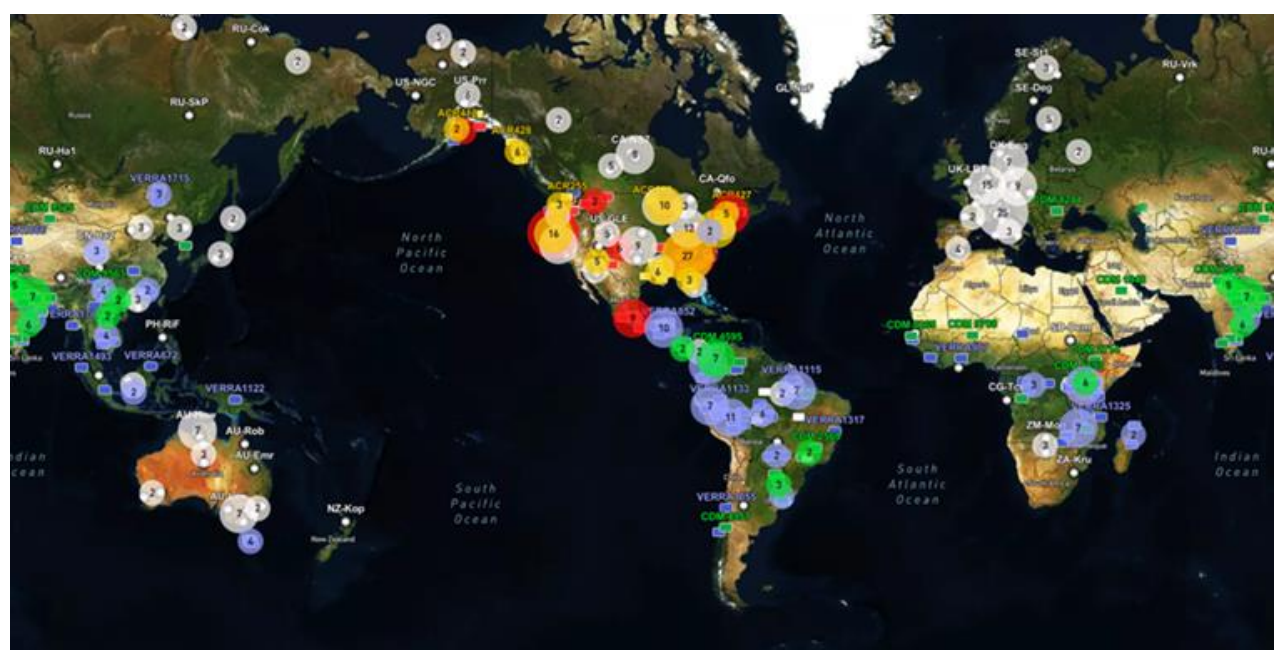

Figure 1. Site locations for data used in this study. An interactive map can be found at: https://planetalphaforest.earth $/ \mathrm{map} /$.

\subsection{Data collection}

Each protocol database was built row by row by finding project areas, credits issued, dates, locations, and any information that could be relevant from each project documentation. The following paragraphs provide detailed information about the database structure of each protocol.

CARB-CAR offsets and project sizes in the categories "Improved Forest Management" and "Avoided Conversion" were obtained from https://thereserve2.apx.com/myModule/rpt/myrpt.asp? $\mathrm{r}=111$ by following each link to each respective project information page (links under the column "Documents"). Then, project sizes were copied manually from the "Projects submittals", while the tab "Project Emission/Reductions" on that page lists gross yearly credits issued named as "Quantity of Offset Credits".

An ACR credits database was built for all the projects in the category "Forest Carbon" from each project documents, which can be accessed at https://acr2.apx.com/myModule/rpt/myrpt.asp?r=111 following the links from the column "Documents". Each project size and location were retrieved manually from the documents labeled as "Offset Project Listing Form" and "Project Submittal", while carbon offsets for each period were obtained from the "Verification Statement" reports. Gross values, as offsets assigned plus buffer credits, were used as total yearly credits.

CDM offsets from the category "Afforestation and Reforestation" were obtained from its webpage (https://cdm.unfccc.int/Projects/projsearch.html) under the column "Reductions". Afterwards, by following each project links to their information pages, the project areas were copied manually from their corresponding "Project design" documents.

VERRA dataset was downloaded from https://registry.verra.org/app/search/VCS selecting all the projects under the category "Agriculture Forestry and Other Land Use". Then, the database was completed with the sizes of the projects, which were obtained individually from their respective description documents that can be accessed by following its respective links. To calculate daily offsets for each site ("ID" column), the values from the column "Credits Quantity Issued" were summed over each "Retirement/Cancellation Date".

In contrast to the data from the protocols, the NEE database was downloaded directly without needing to review each site individually. FluxNet subset 
(https://fluxnet.org/data/fluxnet2015-dataset/subset-data-product/; [19] was used as daily and annual NEE databases (spreadsheets labeled as "DD" and "YY", respectively). Columns "NEE_VUT_REF", "GPP_NT_VUT_REF" and "RECO_NT_VUT_REF" were used in calculations that involved NEE, GPP and Reco, respectively. This implies that the GPP and Reco used were calculated with the nighttime approach from [28], while NEE was already filtered and gap-filled with the methodology described in that publication.

\subsection{Data availability}

The protocol data that support the findings of this study are available @ https://data.world/bmarinob. FluxNet2015 NEE subset [19] can be found at (https://fluxnet.org/data/fluxnet2015-dataset/subset-data-product/). The calculations are detailed in the Methods section.

\subsection{Statistical calculations}

A means two-tailed t-test was performed to evaluate if NEE data had the same mean as each of the protocol datasets (yearly: CARB-CAR, ACR, and CDM; daily: VERRA), by choosing H0: "FluxNet2015 data has the same mean as Protocol Name" and H1: "FluxNet2015 data and Protocol Name have different means". Trends in the time series were not considered. The calculation was done in Python 3.7 with SciPy 1.4.1 library using the function "scipy.stats.ttest_ind()", which returned the statistics " $\mathrm{t}$ " from Eq. 1 and its respective P-values. Eq. 1 requires the estimation of each sample mean ( $\mathrm{x}_{1}$ and $\left.\mathrm{x}_{2}\right)$ and standard deviation ( $\mathrm{s}_{1}$ and $\mathrm{s}_{2}$ ). The t-statistic follows a t-student distribution with $\mathrm{n}_{1}+\mathrm{n}_{2}-2$ degrees of freedom, where $n_{1}$ and $n_{2}$ are the respective sizes of the samples. $x_{1}, s_{1}$ and $n_{1}$ correspond to the FluxNet2015 dataset, while $\mathrm{x}_{2}$, S2 and $\mathrm{n}_{2}$ to the protocols.

$$
t=\frac{x_{1}-x_{2}}{\sqrt{\frac{\left(s_{1}\right)^{2}}{n_{1}}+\frac{\left(s_{2}\right)^{2}}{n_{2}}}} \quad(\mathrm{Eq} 1)
$$

Absolute and percentage errors if Reco was neglected were calculated assuming that, in that case, NEE should be equal to GPP (Eq. 2 and 3). For this calculation, FluxNet yearly data without missing values in both variables was used.

$$
\begin{aligned}
& \% \text { Error }=\frac{G P P-N E E}{N E E} \quad(\mathrm{Eq} 2) \\
& \text { Absolute Error }=G P P-N E E
\end{aligned}
$$

\section{Results}

A comparison of the features for each CFCP is summarized in Table 1. The dispersion of data for CFCPs and for NEE data are first characterized by box plots in $\mathrm{gC}^{-2} \mathrm{y}^{-1}$ for NEE, CARB-CAR, ACR, CDM, and in $\mathrm{gC} \mathrm{m}^{-2} \mathrm{~d}^{-1}$ for VERRA (Fig. 2). Probability histograms are employed to identify the structural features of CFCP annual net forest carbon that delimit CFCP values to less than or equal to zero $\left(\leq 0 \mathrm{gC} \mathrm{m}^{-2} \mathrm{y}^{-1}, \mathrm{~d}^{-1}\right)$ relative to NEE values (Fig. 3.A-D). Probability histograms are also employed to identify the NEE component, GPP or Reco, that accounts for the absence of CFCP positive values relative to NEE values (Fig. 3.B,D). Lastly, a time series of annual data for CARB-CAR, ACR, and the CDM are then shown relative to NEE noting the threshold for a $5 \%$ increase over contemporaneous NEE values (Fig. 4).

\subsection{Table 1. Comparison of CFCP Features (Annotations Provided in Appendix 1.)}

Table 1 (items \#1 - 22) identifies the CFCP protocol information sources and defining features addressed in this study including registries for the CARB [1], [29], the CAR [30] (CARB and CAR employ identical protocols and are referred to as CARB-CAR), the ACR [31], VERRA) [32], and the CDM [33]. Project locations are shown on an interactive map: https://planetalphaforest.earth/map/, Figure 1. NEE data are provided for comparison. Referring to Table 1, items \#7-10, CFCP offsets reported here covered 15,034,700 hectares (ha) corresponding to 566,434,098 offsets ( $\mathrm{tCO}_{2} \mathrm{e}$ ) with an estimated value of $\sim \$ 15.7 \mathrm{Bn}$ USD (USD $\$ 10 \mathrm{tCO}_{2}$, the initial price floor for CARB-CAR offsets [34]). Verra holds $80 \%$ of 
the land, $50 \%$ of offsets, and 19\% of revenue with an average price of US\$3. In contrast, CARB-CAR holds $7 \%$ of the land, $29 \%$ of offsets, and $74 \%$ of revenue with an average compliance price of US\$14.13. ACR holds $13 \%$ of the land, $20 \%$ of offsets, and $7 \%$ of revenue with an average price of US\$3. CDM holds $1.7 \%$ of land reflecting exceedingly small project sizes and $0.01 \%$ revenue reflecting the lowest pricing of $\sim$ US\$00.12. CARB-CAR offsets represent $\sim 80 \%$ of offsets issued [35] compared to $20 \%, 42 \%$, and $0.8 \%$ for ACR, VERRA, and CDM, respectively, emphasizing the reliance on forest carbon offsets for CARB-CAR to meet the AB-32 and AB-398 emission reduction mandates [34], [36]. CARB$\mathrm{CAR}$ also hosts the highest average ratio of offsets to land area of $178.2 \mathrm{tCO}_{2} / \mathrm{ha}, \sim 3 \mathrm{x}, 8 \mathrm{x}$, and $21 x$ that for ACR, VERRA, and the CDM, respectively, (Item \#11), emphasizing the differentiation of compliance versus voluntary offsets (item \#12). CFCP $\mathrm{tCO}_{2}$, required to represent net greenhouse gas reductions (item \#13), are expressed as $\mathrm{gC} \mathrm{m}^{-2} \mathrm{y}^{-1}$ are based on minimal forest mensuration combined with forest growth models [1], [37], are exclusive of data for soil carbon by default (e.g., soil organic matter, soil efflux of $\mathrm{CO}_{2}$ ), are typically subject solely to desk review by selected third-party verifiers ( 1 - 3 years intervals), are subject to invalidation at 3- or 8-year intervals, and lack a central repository for raw data supporting CFCP (items \#14 - 21). Referring to items \#12-14, higher pricing for compliance versus voluntary offsets appears to be arbitrary as both offset categories are based on structurally similar CFCPs implying that offset status is vested in executive boards or similar entities [14], [15] causing financial inequalities across forest landscapes.

In contrast, eddy covariance, a universally accepted atmospheric micrometeorological method quantifying net $\mathrm{CO}_{2}$ flux (NEE; NEE = GPP - Reco) [16], [38], directly samples $\mathrm{CO}_{2}$ and the wind field at high frequency above the forest [16], is verified against referenced independent third-party international standards [39], [40], offers immediate data invalidation and data removal within minutes based on remotely acquired instrumentation diagnostics or system failure flags resulting from QA/QC processing [19], provides uncertainty estimation procedures and uncertainty data [19], and affords open access to global NEE data repositories with standard reporting formats (e.g., QC flag (NEE_VUT_REF_QC)[41]-[44]. Eddy covariance measurements can be replaced if they were taken under low turbulence conditions [45] or gap-filled if there were short periods of missing values (up to three months approximately [28], [46], [47]). NEE establishes hourly to annual time series [48], [49] reporting absolute changes in net sequestered forest carbon relative to a zero instrumental baseline where positive values are emissions to the atmosphere and negative values are carbon stored in the forest ecosystem. NEE methodology is not subject to and independent of unprovable counterfactual arguments, arbitrary soil carbon baselines, or use of large administrative Forest Inventory and Analysis (FIA) areas as units of analysis that mask local variability in forest composition [34], [50]. NEE baselines are defined by time series data spanning hours to years [48], [49], [51]. Such measurement-defined baselines could be employed to create global and regional indices of net forest carbon flux behavior similar to those employed for forest timber pricing [52]. Diverse peer-reviewed models employ NEE data to determine soil carbon efflux [53] and effects of climate change across landscapes including forest conservation [54]. Eddy covariance and CFCP methods for determination of net sequestered forest carbon results are, in principle, comparable according to the equivalence of Net Ecosystem Production (NEP), primarily based on biometric data, and NEE, based on forest tower flux measurement (NEP = - NEE) [55]-[57]. However, the labor and cost requirements for comprehensive NEP biometry to approximate NEE are likely prohibitive for CFCP, particularly for large project areas (e.g., 100,00 to 1,000,000 acres) relying principally on the measurement of tree diameter at breast height (Table 1). A complete biometric accounting would require, throughout the year, foliage, stem, and branch diameters, litter fall decomposition, the weight of coarse and fine roots, and chamber measurements of soil $\mathrm{CO}_{2}$ efflux for each project timber plot, the latter recognized as a significant source of uncertainty for biometric methods [55], [57]. Eddy covariance $\mathrm{NEE} \mathrm{CO}_{2}$ projects have been widely published 
with $~ 600$ peer-reviewed journal articles (item \#22) [38]; to our knowledge, CFCP methods, per se, have not been journal peer-reviewed. Considered together (items \#1 - 22), the eddy covariance NEE method provides an improved, science-based universal metric for harmonizing carbon trading and markets, and can be readily applied to the verification of $\mathrm{CH}_{4}$ and $\mathrm{N}_{2} \mathrm{O}$ emission reductions [20], [51], [58], [59]. However, NEE research methods clearly require technological development and cost reduction to accommodate commercial projects including scale-up of NEE data from the NEE footprint to larger areas, controlling for lateral flux leakage, and accounting for the uncertainties of $\mathrm{NEE} \mathrm{CO}_{2}$ flux data. The limitations cited are under active development by the forest research and management communities worldwide [19], [60], [61]. 


\begin{tabular}{|c|c|c|c|c|c|c|}
\hline & Feature & $\mathbf{N E E}^{1}$ & CARB/CAR ${ }^{2}$ & ACR & VERRA & CDM \\
\hline 1 & website & Fluxnet.org & arb.ca.gov & $\begin{array}{c}\text { americancarbonregi } \\
\text { strv.org }\end{array}$ & verra.org & $\underline{\text { cdm.unfecc.int }}$ \\
\hline 2 & Registry & NA & $\begin{array}{c}\mathrm{CAR}^{3}, \mathrm{VERRA}^{3}, \\
\mathrm{ACR}^{3}\end{array}$ & $\mathrm{ACR}$ & VERRA & $\mathrm{CDM}^{5}$ \\
\hline 3 & First Data Year & 1992 & $2001 / 2002$ & 2009 & 1999 & 2006 \\
\hline 4 & \# Projects & 206 & $443 / 121$ & 96 & 138 & 66 \\
\hline 5 & $\begin{array}{l}\text { \# Project Years or } \\
\text { Days }\end{array}$ & $\begin{array}{c}1448 \text { Yrs } \\
545,323 \text { days }\end{array}$ & 519 Yrs & 185 Yrs & 6466 Days & 67 Yrs \\
\hline 6 & $\begin{array}{l}\% \text { Forestry/Land } \\
\text { Use Projects }\end{array}$ & $100 \%^{4}$ & $80 / 25$ & 20 & 42 & 0.8 \\
\hline 7 & Land Area (ha) $)^{5}$ & NA & 925,252 & $1,887,866$ & $11,956,885$ & 264,697 \\
\hline 8 & $\begin{array}{l}\text { Carbon Offsets } \\
\left(\mathrm{tCO}_{2} \mathrm{e}\right)^{5}\end{array}$ & NA & $164,910,753$ & $113,013,103$ & $286,277,319$ & $2,232,923$ \\
\hline 9 & Value $\$ 10 \mathrm{O} 2 \mathrm{e}^{6}$ & NA & $\$ 11.7 \mathrm{Bn}$ & $\$ 1.1 \mathrm{Bn}$ & $\$ 2.9 \mathrm{Bn}$ & $\$ 22.3 \mathrm{Mn}$ \\
\hline 10 & $\begin{array}{l}\text { Ave. Price } \mathrm{tCO}_{2} \mathrm{C} \\
\text { (2019) }\end{array}$ & NA & US $\$ 14.13^{7}$ & $\mathrm{US} \$ 3.00^{8}$ & US $\$ 3.00^{8}$ & $\begin{array}{l}\mathrm{US} \$ 0.15- \\
0.24 / \mathrm{tCO} 2 \mathrm{e}^{8}\end{array}$ \\
\hline 11 & Ave. $\mathrm{tCO}_{2} / \mathrm{ha}$ & NA & 178.2 & 59.9 & 23.9 & 8.4 \\
\hline 12 & Offset Type & $\begin{array}{c}\text { Compliance, } \\
\text { Voluntary }\end{array}$ & $\begin{array}{l}\text { Compliance }^{8} \\
\text { ARBOC's }{ }^{9}\end{array}$ & $\begin{array}{l}\text { Compliance }^{10}, \\
\text { Voluntary, VER's }{ }^{8}\end{array}$ & Voluntary, VCU's ${ }^{8}$ & Voluntary, CERs ${ }^{8}$ \\
\hline 13 & $\begin{array}{l}\text { Measurements } \\
\mathrm{gC} \mathrm{m}^{-2} \mathrm{yr}^{-1} / \mathrm{d}^{-1}\end{array}$ & $\begin{array}{c}\text { NEE, } \mathrm{CO} 2, \mathrm{H} 2 \mathrm{O}, \\
\text { Energy }\end{array}$ & Net Forest Carbon ${ }^{11}$ & Net Forest Carbon ${ }^{12}$ & Net Forest Carbon ${ }^{13}$ & Net Forest Carbon ${ }^{14}$ \\
\hline 14 & $\begin{array}{l}\text { Methods } \\
\mathrm{NEE}=\mathrm{GPP}+\mathrm{R}_{\text {eco }}\end{array}$ & $\begin{array}{c}\mathrm{CO}_{2} \text { Flux, Eddy } \\
\text { Covariance }\end{array}$ & $\begin{array}{l}\text { Forest Biometry \& } \\
\text { Models }^{11}, \quad \text { gaseous }\end{array}$ & $\begin{array}{l}\text { Forest Biometry, } \\
\text { Models }^{12}, \quad \text { gaseous }\end{array}$ & $\begin{array}{l}\text { Forest } \text { Biometry }^{13} \\
\text { Models, }\end{array}$ & $\begin{array}{l}\text { Forest } \text { Biometry }^{14} \text {, } \\
\text { Models, } \quad \text { gaseous }\end{array}$ \\
\hline 15 & Soil Protocol & NEE & Optional ${ }^{11}$ & Optional $^{12}$ & Optional ${ }^{13}$ & Optional ${ }^{14}$ \\
\hline 16 & Soil Default & NEE & Excluded $^{11}$ & Excluded $^{12}$ & Variable $^{13}$ & Excluded $^{14}$ \\
\hline 17 & $\begin{array}{l}\text { Third-party } \\
\text { Verification }\end{array}$ & $\begin{array}{l}\text { References, } \\
\text { Standards }{ }^{15}\end{array}$ & $\begin{array}{l}\text { Accredited by } \\
\mathrm{ARB}^{16}\end{array}$ & $\begin{array}{l}\text { Accredited by } \\
\mathrm{ACR}^{16}\end{array}$ & $\begin{array}{l}\text { Accredited by } \\
\text { VERRA }^{16}\end{array}$ & $\mathrm{DOE}^{17}$ \\
\hline 18 & Invalidation Criteria & $\begin{array}{l}\text { Outlier Detection, } \\
\text { filtering methods } \\
\text { (Papale et al., 2006) }\end{array}$ & $\begin{array}{l}\text { CARB }+5 \% \\
\text { Overcrediting }{ }^{18} / \mathrm{CA} \\
\mathrm{R}^{19}\end{array}$ & None $^{20}$ & None $^{16}$ & None $^{16}$ \\
\hline 19 & Invalidation Period & Minutes to Hours ${ }^{21}$ & 3 to 8 Years $^{22}$ & None $^{16}$ & None $^{16}$ & None $^{16}$ \\
\hline 20 & $\begin{array}{l}\text { Biometric Survey } \\
\text { Frequency }\end{array}$ & $\begin{array}{c}\text { Research } \\
\text { Dependent }^{23}\end{array}$ & 6,12 Years $^{24}$ & 10 Years $^{12}$ & 10 Years $^{13}$ & 5 Years $^{14}$ \\
\hline 21 & $\begin{array}{l}\text { Raw Data } \\
\text { Repository }\end{array}$ & $\begin{array}{c}\text { National, } \\
\text { International }\end{array}$ & None & None & None & None \\
\hline 22 & $\begin{array}{l}\text { Journal Peer } \\
\text { Reviewed }\end{array}$ & $\sim 600^{17}$ & None & None & None & None \\
\hline
\end{tabular}




\subsection{Boxplots for Annual (NEE, CARB-CAR, ACR, CDM) and Daily Forest Carbon Seques- tration and Statistical Analyses}
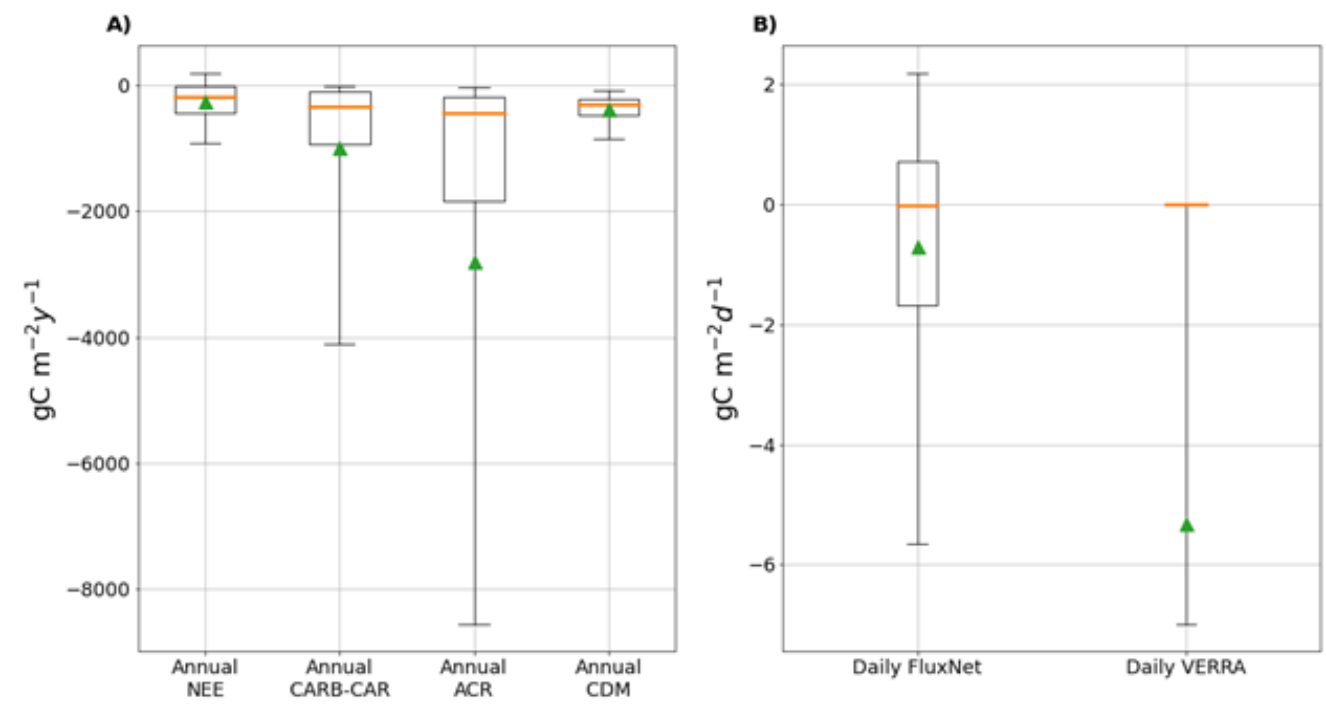

Figure 2: A) Annual boxplots in gC $\mathrm{m}^{-2} \mathrm{y}^{-1}$ for FluxNet2015 NEE [19], CARB-CAR, ACR and CDM databases. B) Daily boxplots in $\mathrm{gC} \mathrm{m}^{-2} \mathrm{~d}^{-1}$ for daily FluxNet2015 and VERRA databases. Mean (green triangles), median (orange lines), 1st and 3rd quartiles (box) and 5 and 95 percentiles (whiskers) are represented. The box from VERRA dataset is too small to be seen at this scale.

Boxplots (excluding extreme outliers) shown in Figure $2(\mathrm{~A})$, for annual NEE $(\mathrm{n}=1448)$, CARB-CAR $(\mathrm{n}=519), \operatorname{ACR}(\mathrm{n}=185)$ and CDM $(\mathrm{n}=67)$, data $\left(\mathrm{gC} \mathrm{m}^{-2} \mathrm{y}^{-1}\right)$, and (B) VERRA $(\mathrm{n}=6466)$ and NEE $(\mathrm{n}=528,889)$ representing daily data according to the VERRA data reporting format $\left(\mathrm{gC} \mathrm{m}^{-2} \mathrm{~d}^{-1}\right)$, characterizes overall data dispersion for each protocol. Horizontal lines (orange) and triangles (green) represent medians and means, respectively. The boxes represent the values between the 25th and 75th percentiles; whiskers include the numbers inside the 5th and 95th percentiles. CARB-CAR and ACR data have the largest variance, skewness towards negative values, and outliers (extreme outliers have been removed to facilitate visibility of the bulk data), relative to the annual NEE median, while the CDM is less variable, lying within the interquartile range of the NEE data. Compared with CARB-CAR and NEE dispersion, ACR mean, and SD dispersion are more extreme. The VERRA and CARB-CAR daily data distributions are correspondingly inconsistent with the NEE means and standard deviations of $-257 \pm 392.5$, compared to $-983.6 \pm 3,428$ and $-2,798.9 \pm 15,317.5$, for CARB-CAR and ACR data, respectively, emphasizing the exceptionally large numerical differences between means and SDs for the datasets. Table 2 summarizes the results of two-tailed statistical analysis to accompany the dispersion data. The null hypothesis, $\mathrm{H0}$, that the CFCP values are from the same population as represented by the NetFlux2015 data, is rejected at the $99.99 \%, 99.99 \%, 95 \%$ and $99.99 \%$ for CARB-CAR, ACR, CDM and VERRA, respectively. Referring to Table 2, the CFCP $\leq 0$ delimit for values (note: 2 ACR positive values are reported out of 185 total values included in this analysis) constitutes the key structural feature that intricately links CFCPs. This link inevitably leads to incomplete accounting for forest carbon offset production. In addition, The CARB-CAR and ACR protocols share similarities in having higher means, $\sim 4 \mathrm{x}$ and $\sim 11 \mathrm{x}$ larger relative to NEE, and SD's of $9 \mathrm{x}$ and 39x larger, relative to NEE, respectively. The dispersion data also point to common methodologies and processes employed by CARB-CAR and ACR protocols. Similarly, there is a large difference between VERRA and NEE daily data. The VERRA mean and SD are $\sim 8 \mathrm{x}$ and $\sim 27 \mathrm{x}$ larger than daily NEE 
values, respectively. The VERRA maximum value of $\sim 0$ and minimum of $-4,706.3$ (gC m$\left.{ }^{2} \mathrm{~d}^{-1}\right)$, relative to NEE values of 23.8 and $-25.9\left(\mathrm{gC} \mathrm{m}^{-2} \mathrm{~d}^{-1}\right)$ respectively, further differentiate VERRA data as not reflective of natural patterns of forest carbon dynamics and NEE. Excluding positive values unavoidably introduces carbon accounting errors resulting in a median of $\sim 247 \%$ or $-269 \mathrm{gC} \mathrm{m}^{-2} \mathrm{y}^{-1}$ (Table A1.) over the entire FluxNet2015 database. Taken together with the statistical results suggesting that CFCP and NEE are likely drawn from different populations, the data confirm that CFCP structures and calculations delimit positive emissions to the atmosphere on an annual and daily carbon accounting basis. The unaccounted positive emissions represented by ecosystem respiration (Reco comprised of heterotrophic and autotrophic respiration) triggers automatic debits to the net forest carbon project offset ledger resulting in overcrediting of offsets [7], [20], [49]. Consequently, CFCP project offsets, unless proven otherwise, should be adjusted downward, or voided as the basis for valid material transactions, as previously reported [7], [9], [62].

Table 2. Daily and yearly statistics for each dataset in $\mathrm{gC} \mathrm{m}^{-2} \mathrm{y}^{-1}$ and $\mathrm{gC} \mathrm{m}^{-2} \mathrm{~d}^{-1}$, respectively. The Means T-tests were performed between NEE and CARB-CAR, ACR and CDM, and between FluxNet NEE and VERRA. The asterisks indicate if $\mathrm{H} 0$ can be rejected at $95 \%\left({ }^{*}\right)$, $\left.99 \%{ }^{* *}\right)$ or $\left.99.99 \%{ }^{* * *}\right)$ level of confidence in a two tailed t-test.

\begin{tabular}{|c|c|c|c|c|c|c|}
\hline Database & $\begin{array}{c}\text { FluxNet } \\
\text { NEE }\end{array}$ & $\begin{array}{l}\text { CARB- } \\
\text { CAR }\end{array}$ & ACR & CDM & $\begin{array}{c}\text { FluxNet } \\
\text { NEE }\end{array}$ & VERRA \\
\hline Frequency & Annual & Annual & Annual & Annual & Daily & Daily \\
\hline Mean & -257.60 & -983.61 & $-2,798.93$ & -373.72 & -0.7 & -5.31 \\
\hline Median & -182.45 & -344.37 & -436.16 & -298.43 & -0.0067 & -0.0012 \\
\hline Min & -2505.06 & $-69,020.49$ & $-204,917.54$ & $-1,038.79$ & -25.9 & -4706.33 \\
\hline Max & 2129.23 & 0.00 & 675.36 & -7.55 & 23.8 & -0.00002 \\
\hline Sd & 392.46 & 3428.01 & $15,317.54$ & 259.64 & 2.49 & 66.69 \\
\hline Num & 1448.00 & 519 & 185 & 67 & 528,889 & 24,771 \\
\hline t-statistic & --- & 7.19 & 6.31 & 2.4 & --- & 49.5 \\
\hline $\begin{array}{l}\text { Degrees of } \\
\text { freedom }\end{array}$ & --- & 1967 & 1633 & 1952 & --- & 601887 \\
\hline P-value & --- & 3.96 E-15 & 3.58 E-10 & $1.66 \mathrm{E}-2$ & --- & $0.00 \mathrm{E} 0$ \\
\hline $\begin{array}{l}\mathrm{HO} \\
\text { rejection }\end{array}$ & --- & $* * *$ & $* * *$ & * & --- & $* * *$ \\
\hline
\end{tabular}




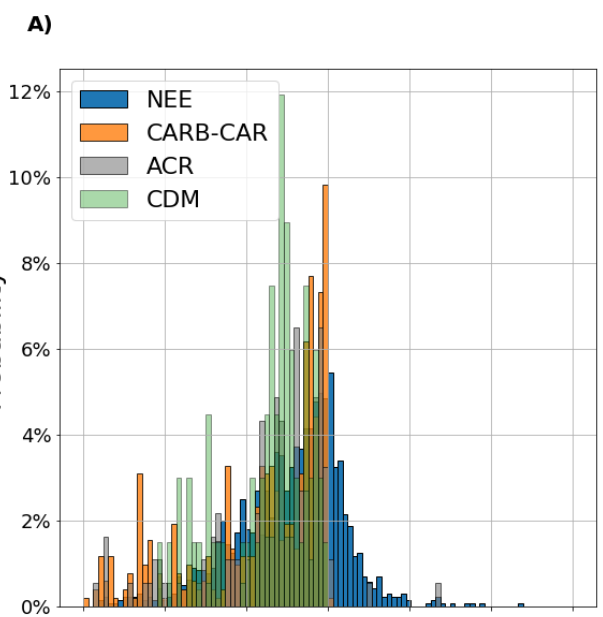

C)

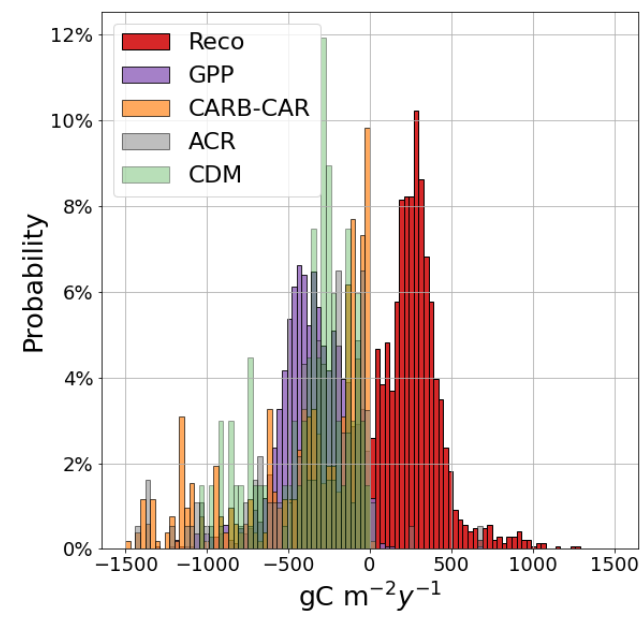

B)

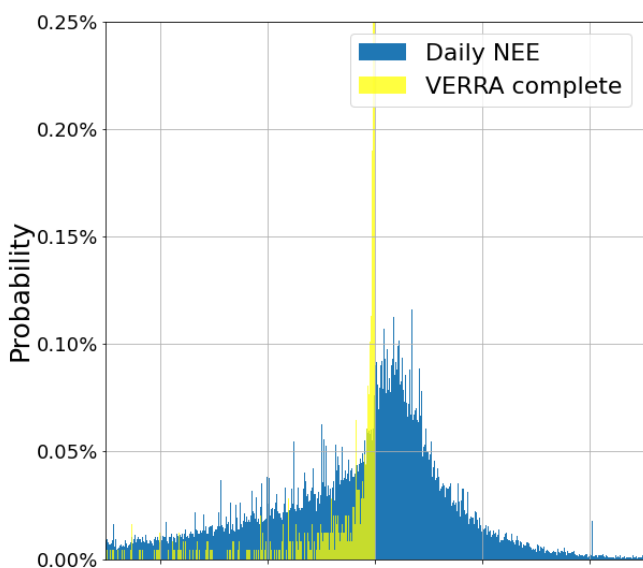

D)

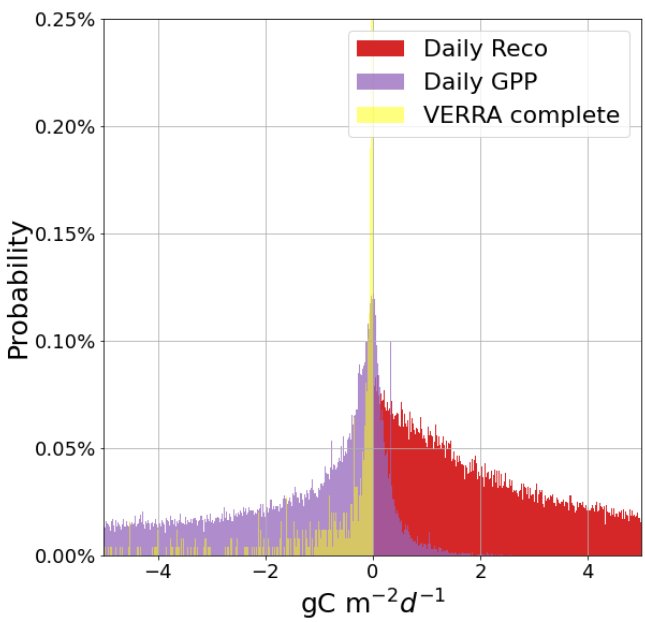

Fig. 3. CARB-CAR (orange), ACR (grey) and CDM (green) histograms in $\mathrm{gC}^{-2} \mathrm{y}^{-1}$ along with A) Annual FluxNet2015 NEE (blue), and C) Annual Reco (red), and GPP (purple). Only values between -1500 and 1500 $\mathrm{gC} \mathrm{m}^{-2} \mathrm{y}^{-1}$ are shown, with a bin size of $30 \mathrm{gC} \mathrm{m}^{-2} \mathrm{y}^{-1}$. All VERRA (yellow) histograms with B) Daily FluxNet2015 NEE (blue), D) Daily Reco (red), GPP (purple), for carbon sequestration values between -5 and $5 \mathrm{gC} \mathrm{m}^{-2} \mathrm{~d}^{-1}$. The bin size is $0.0025 \mathrm{gC} \mathrm{m}^{-2} \mathrm{~d}^{-1}$. Front panel histograms are slightly transparent to allow the visualization of the overlapping values from the histograms plotted on the background. Each panel histogram order, from back to front, is A) NEE (back), CARB-CAR (middle-back), ACR (middle-front) and CDM (front) B) Daily NEE (back) and VERRA complete (front) C) Reco (back), GPP (middle-back), CARB-CAR (middle), ACR (middle-front) and CDM (front) D) Daily Reco (back), Daily GPP (middle), VERRA complete (front).

Figure 3.A,B shows data for CFCPs compared with NEE $\left(\mathrm{gC} \mathrm{m}^{-2} \mathrm{y}^{-1}\right)$ plotted as probability histograms (A) NEE (blue), CARB-CAR (orange), ACR (gray), and CDM (green); (B) NEE $\left(\mathrm{gC} \mathrm{m}^{-2} \mathrm{~d}^{-1}\right.$ ) (blue), and VERRA (yellow). Fig. 3.C,D shows data for CFCPs compared with Reco and GPP $\left(\mathrm{gC} \mathrm{m}^{-2} \mathrm{y}^{-1}\right)$ as probability histograms for (C) Reco (red), GPP (purple), CARBCAR (orange), ACR (gray), CDM (green); (D) $\left(\mathrm{gC} \mathrm{m}^{-2} \mathrm{~d}^{-1}\right)$ daily Reco (red), daily GPP (purple),VERRA (yellow). Fig. 3.A-D clearly shows and confirms that the probability histograms for CFCPs exclude values $\leq 0\left(\mathrm{gC} \mathrm{m}^{-2} \mathrm{y}^{-1}\right.$ or $\left.\mathrm{d}^{-1}\right)$ for all protocols, with few isolated outliers as noted in the histograms, consistent with the dispersion and statistical analysis results (Fig. 2, Table 2). In particular, VERRA sharply delimits values representing daily project data with most values skewed towards zero (Fig.3.B,D) contrasting with FluxNet2015 (NEE, Reco, GPP) data representing a global forest data set [19]. Thus, Fig. 3 
data imply that CFCP biometric values and proxy model simulations do not represent the range of known NEE and corresponding Reco and GPP values [18].

\subsection{Time Series Data \& 5\% Overcrediting Threshold}

An analysis of the time series data and variance for CFCP data compared to NEE was undertaken to indicate when annual average CFCP data were greater than $5 \%$ relative to NEE values for the same year. Fig. 4 shows the occurrence of a $5 \%$ over-crediting of CFCP project annual offsets relative to values represented by annual NEE. The CARB-CAR protocol uses this criteria to invalidate a project [63] and is used here as a diagnostic for related CFCP protocols. In a previous analysis, NEE values representing the known range of values [18], [64] were used for comparison with CARB-CAR [7]; a similar approach is used here with updated NEE values [19]; the comparison has no regulatory application. Referring to Figure 4 , the error bars are $5 \%$ of the highest yearly sequestration in each time series, which were 2015, 2019, and 2015, for CARB, ACR, and CDM, respectively, and applied to protocol values across remaining years for that protocol, as a conservative measure, and to apply the same criteria across protocols. Figure 4 shows annual data for NEE (blue), CARB-CAR (orange), ACR (yellow), and CDM (green) from 1992 to 2020; NEE values are shown as positive values. Referring to Figure 4, the CARB-CAR projects, extending beyond those reported previously [7], show no intersection between the admissible interval and the NEE measurements for any of the overlapping years (2001-2015). While the NEE data (FLUXNET 2015) do not extend beyond 2015, the CARB-CAR values for the years 2016 to 2019 are, on average, $\sim 3 x$ that of NEE values reported previously [7]. Mean annual ACR values recorded from 2009 to 2012 are within the NEE range, but thereafter exhibit higher average values for 2013 to 2020 than for NEE and CARB-CAR values. The annual mean and SD for CARB-CAR are $\sim 4 \mathrm{x}$ and $\sim 9 \mathrm{x}$ that for NEE, consistent with previously reported analysis [7]. The ACR mean and SD are $\sim 11 \mathrm{x}$ and $\sim 39 \mathrm{x}$ that for NEE, respectively. The CDM annual values appear within the range of available NEE values and would not be considered invalid based on the $5 \%$ threshold applied to CARB-CAR and ACR. However, exclusion of positive values (Figure 3.A,C; Table 2) implies that CDM results are arguably unreliable.

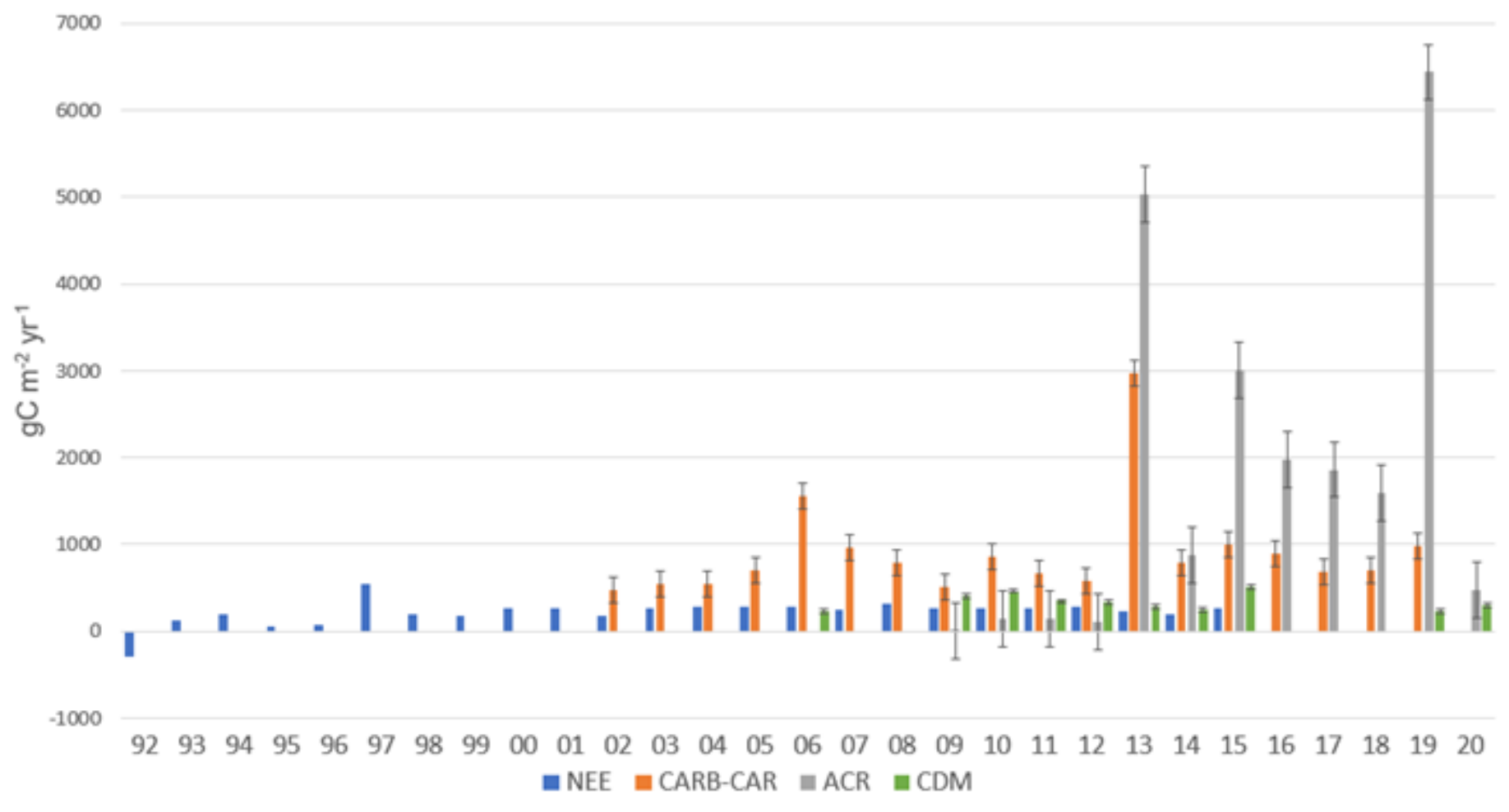


Fig. 4 NEE (blue), CARB-CAR (orange), ACR (grey) and CDM (green) yearly carbon sequestrated in gC $\mathrm{m}^{-2} \mathrm{y}^{-1}$. The error bars are the $5 \%$ of the highest yearly sequestration in each time series, which were 2015, 2019, and 2015 for CARB, ACR, and CDM, respectively. VERRA daily data are not shown. Positive values are sequestration by the vegetation.

\section{Discussion}

This study establishes that CFCP, in addition to excluding direct $\mathrm{CO}_{2}$ measurements, specifically excludes positive carbon emission values derived from biometric and/or model simulations and is a central structural feature across the five protocols analyzed. The absence of positive values correlates with a zero-threshold for CFCP offset carbon accounting, eliminating $\mathrm{CO}_{2}$ sources to the atmosphere embedded in all forest ecosystems as respiration (Reco). While CFCPs generally provide an option for soil carbon, it is excluded by design or default (Table 1, item \#'s 15,16) [7], suggesting that CFCPs do not fulfill the intended protocol objectives for a justifiable net forest carbon determination. Consequently, CFCP offsets cannot represent net forest carbon emission reductions or achieve the methodological or regulatory objectives claimed by each protocol (Table 1, item \#'s 2,13; Figures 2-4). CFCPs appear to represent a variant of methods commonly employed to document and manage timber resources [65], however, a complex and expensive regulatory system is not required for timber management. This study emphasizes that complete carbon accounting is required to track and commercially monetize net forest carbon sequestration, regardless of protocol and specifications, and that improvements and alternatives to CFCPs should be considered and be subject to scientific peer-review [20].

The soil carbon component of forest ecosystems, typically comprising up to $\sim 3 x$ that for above ground carbon [53], cannot be ignored. Moreover, temporal and spatial analysis of the soil column carbon composition is difficult to characterize [48], [49], [66], a recognized weakness of biometric forest carbon protocols [56], [57], and a challenge to CFCP improvement. NEE integrates all vertical positive and negative $\mathrm{CO}_{2}$ emissions for the forest providing a carbon sequestration balance. In contrast, statistical comparative analysis of CFCP and NEE results is consistent with exclusion of soil respiration, accounting for up to $82 \%$ of annual net forest carbon sequestration resulting in a median error of $\sim 247 \%$ and consistent with overcrediting (Table A1.). An annual error of up to 2,256\% relative to eddy covariance NEE results was reported for a single site, the Howland Forest, Maine, USA, the only site where both CFCP and eddy covariance approaches overlap. Moreover, CFCPs (i.e., CARB-CAR) are tied to a 100-year monitoring requirement, typically against an estimated, invariant and default soil carbon baseline (Table 1) [34]. Mandating invariant soil baselines is unrealistic as the soil carbon response to climate change over the coming decades and century [53] are not accounted for in CFCPs. Following directly from the zero-threshold structure identified in this study, CFCP lacks sensitivity to ecosystem switching from net carbon sink to positive source values [7], a critical capability to manage intermittent carbon sequestration [67], and to detect climate change effects on ecosystems, arguably criteria for invalidating CFCPs for these purposes. Finally, CFCP data do not reflect the natural patterns of time series carbon dynamics established by global diverse eddy covariance research sites at annual or daily resolution (Fig. 3.A-D). The high interannual variance for NEE, for the purposes of carbon monitoring, implies that direct measurement is required to capture the dynamic nature of changes in annual net forest carbon storage. Discerning changes in annual net forest carbon from forest biometric surveys very 6 to 12 years using proxy forest composition and model growth simulations are not supported by the results of this study. Considered together, we conclude that CFCPs, based on incomplete carbon accounting, are not capable of advancing forest carbon quantification methodology or technology to fulfill the requirements for financial carbon markets, or to manage and track forest carbon under changing climate scenarios including unpre- 
dictable feedbacks [68]. Indeed, CFCP results cannot be regarded as reliable, even if selected results appear reasonable, as for the CDM (Table 2), given that positive NEE values are excluded from calculating a net carbon balance. Given the enigma of persistent deforestation and the $\sim 0.9$ billion hectares of forests available worldwide for large-scale restoration opportunities [69], [70] improvement in forest carbon quantification is an urgent need, and is achievable with existing, proven, direct measurement technology.

Improved and/or alternative forest carbon offset protocols could link the Paris Agreement [71], [72], REDD+ projects [27], community forests and Indigenous Peoples land management projects [73]. Investors, buyers and sellers of compliance or regulatory offsets and voluntary offsets would have access to equivalent $\mathrm{NEE}$ based $\mathrm{tCO}_{2}$ trading units. Features of CFCP including tests for additionality and leakage can operate as needed, although is it increasingly clear that additionality, leakage and setting of baselines are arbitrary, decided on a case-by-case basis, or simply based on default values [14], [15]. Ultimately, verification of net forest carbon sequestration offers the most stringent test of additionality in that each $\mathrm{tCO}_{2}$ traded is validated as "net-additional" in reducing the atmospheric burden of $\mathrm{CO}_{2}$. While the limitations and caveats of the statistical analyses presented here are acknowledged, specifically, the absence of multiple direct site comparisons of NEE and CFCPs, the results clearly indicate that population differences between the two approaches are real, that CFCPs do not fully account for $\mathrm{CO}_{2}$ sources, and are likely in error for net carbon balance results. Such inconsistencies cannot be ignored (see [7] for a detailed list of NEE limitations, caveats and mitigation approaches). Collaboration between CFCPs and eddy covariance research sites is advisable and likely achievable given the $600+$ eddy covariance studies published and expanding networks of eddy covariance sites [74], [75]. Finally, we suggest that CFCPs incorporate a specific terms for ecosystem/and or soil respiration to complete the carbon accounting process required for quantification of net forest carbon sequestration.

\section{Conclusions}

In conclusion, forest carbon commerce is at a crossroads; it is either poised for improvement or it will remain uncertain and limited in applications to manage climate change. Given the absence of natural counterparts ( $R_{\text {eco }}$ in CFCP carbon accounting, improvement of CFCPs to fill gaps is warranted. Protocols that fully account for forest carbon have the potential to catalyze integration of forest landscapes with global financial markets providing pathways to effectively manage, restore and conserve forests. Carbon trading and pricing platforms should be receptive to science-based transformation of CFCPs to verified net forest carbon protocols with social, economic, and diverse planetary benefits now and for future generations.

\section{Supplementary Materials: None.}

Author Contributions: Bruno D.V. Marino conceived the idea and initial writing of the manuscript. Nahuel Bautista was responsible for all numerical analyses and graphics.

Funding: This research received no external funding.

Data Availability Statement: The data are available as follows:

CARB-CAR offsets and project sizes: https://thereserve2.apx.com/myModule/rpt/myrpt.asp?r=111

ACR Data: https://acr2.apx.com/myModule/rpt/myrpt.asp?r=111

CDM Data: https://cdm.unfccc.int/Projects/projsearch.html 
VERRA Data: $\underline{\text { https://registry.verra.org/app/search/VCS }}$

FluxNet2015 Data: https://fluxnet.org/data/fluxnet2015-dataset/subset-data-product/

Summary Data: https://data.world/bmarinob

Summary of Site Locationshttps://planetalphaforest.earth/map/

Conflicts of Interest: The authors declare no conflict of interest.

\section{Appendix}

A1. Annotations for numbered reference supercripts for Table 1; all references are noted in brackets and are incuded in the bibliography.

${ }^{1}$ [19] NEE data source.

2 [76] The California Air Resources Board (CARB) and the Climate Action Reserve (CAR) share identical protocols and project listings and are identified as CARB-CAR.

${ }^{3}$ [15], [77] CAR, VERRA and ACR share selected project listings with CARB-CAR.

${ }^{4}$ [19] FLUXNET sites represent diverse terrestrial ecosystems.

${ }^{5}$ Land area and offset totals represent data reported for each project within a protocol.

${ }^{6}$ A price of $\$ 10$ is employed across protocols to illustrate total gross pre-tax revenue potential comparison

${ }^{7}$ Approximate 2020 vintage settle prices, https://www.californiacarbon.info/

8 [77]

9 [1] ARB Offset Credits

10 [15] Established by ARB compliance process (https://americancarbonregistry.org/california-offsets/compliance-offset-projects)

11[2], [34] Excerpt [3]: Compliance Offset Protocol U.S. Forest Offset Projects. (2015). http://www.arb.ca.gov/cc/capandtrade/protocols/usforest/usforestprojects 2015.htm. Chapter 4. Offset Project Boundary - Quantification Methodology. The GHG assessment boundary, or offset project boundary, delineates the GHG emission SSRs that must be included or excluded when quantifying the net changes in GHG emissions associated with the sequestration of carbon achieved by increasing and/or conserving forest carbon stocks.

12 [22] Excerpt: THE AMERICAN CARBON REGISTRY STANDARD REQUIREMENTS AND SPECIFICATIONS FOR THE QUANTIFICATION, MONITORING, REPORTING, VERIFICATION, AND REGISTRATION OF PROJECT-BASED GHG EMISSIONS REDUCTIONS AND REMOVALS VERSION 6.0, July 2019

https://americancarbonregistry.org/carbon-accounting/standards-methodologies/american-carbon-registry-standard

EMISSIONS RATE OR BENCHMARK (e.g., tons of CO2e emission per unit of output) with examination of sufficient data to assign an emission rate that characterizes the industry, sector, subsector, or typical land management regime, the net GHG emissions/removals associated with the Project Activity, in excess of this benchmark, may be considered additional and credited.

13 [24] Excerpt: 8.4 Net GHG Emission Reductions and Removals, Methodology for Improved Forest Management, Version 1.0, Date of Issue 10 August 2020. https://verra.org/methodology/methodology-for-improved-forest-management/

8.5.1 Summary Net Emissions Reductions and/or Removals Equation The annual net carbon emissions reductions is the actual net GHG removals by sinks from the project scenario 
minus the net GHG removals by sinks from the baseline scenario, were then calculated by applying the leakage and uncertainty discount factors (but not the VCS permanence buffer), on an annualized basis. See also:

https://verra.org/methodology/vm0012-improved-forest-management-in-temperate-and-boreal-forests-ltpf-v1-2/\#

${ }^{14}$ [13] Excerpt: 4. Baseline net GHG removals by sinks. 13. The baseline net GHG removals by sinks shall be calculated as follows.

https://cdm.unfccc.int/methodologies/DB/C9QS5G3CS8FW04MYYXDFOQDPXWM4OE

15 [19], [78] Detection of erroneous $\mathrm{CO}_{2}$ products for NEE calculation (e.g., $\mathrm{mmolCO}_{2}$ $\mathrm{mol}^{-1} \mathrm{CO}_{2}$ ) include automated flagging during QA/QC detection across NEE required variables, including spike detection; calibration of gas analyzers, typically open or closed path infrared gas analyzers are performed at each site according to the type of analyzer and project protocols.

16 [14], [15]

${ }_{17}$ [77] Designated Operational Entity (DOE) accredited by Clean Development Mechanism Executive Board (https://cdm.unfccc.int/DOE/index.html)

18 [79] https://www.arb.ca.gov/cc/capandtrade/offsets/arboc guide regul conform invalidation.pdf

Excerpt: Overstatement of GHG Reductions or Removal Enhancements: ARB offset credits may be invalidated if ARB finds that the amount of the GHG reductions or removal enhancements that were issued credit were overstated by more than 5 percent than what the offset project actually achieved within the applicable Reporting Period.

${ }^{19}$ [80] CAR non-CARB projects are subject to $\pm 5 \%$ of measured or calculated values, however, there are no invalidation determinations.

${ }^{20}$ [22] A materiality threshold of $\pm 5 \%$ is imposed on pending and completed projects, however, there are no invalidation determinations.

${ }^{21}$ [19], [78] There are no formal invalidation periods for NEE data, however, data QA/QC flags identifying instrument or data processing errors can be accessed and identified when they occur either during the high frequency $\mathrm{CO}_{2}$ measurement or summation of flux into 30 minute or hourly fluxes, resulting automatically in a data gap for that period, or invalidation of data for that period.

$22[81]$

${ }^{23}$ [56], [82] Eddy covariance sites often conduct intensive biometric surveys to augment NEE determinations or for other research purposes.

$24[83]$

Table A1. Absolute and percentage errors if Reco is excluded from NEE, calculated over all site years in FluxNet database with non-missing GPP. Negative values are sequestration by the vegetation.

\begin{tabular}{|l|c|c|}
\hline & Absolute error $\left(\mathbf{g C ~}^{-2} \mathbf{y}^{-\mathbf{1}}\right)$ & Percentage error $\left.\mathbf{( \% ~}_{\mathbf{~}}^{-\mathbf{1}}\right)$ \\
\hline Num & 1436 & 1436 \\
\hline Mean & -284 & $-65 \%$ \\
\hline Std & 181 & $13002 \%$ \\
\hline Min & -1789 & $-244720 \%$ \\
\hline Max & 841 & $328977 \%$ \\
\hline \multicolumn{1}{|c|}{ Percentiles } & -936 & $-16357 \%$ \\
\hline $\mathbf{1} \%$ & & \\
\hline
\end{tabular}




\begin{tabular}{|l|c|c|}
\hline $\mathbf{5 \%}$ & -584 & $-2684 \%$ \\
\hline $\mathbf{1 0} \%$ & -469 & $-1086 \%$ \\
\hline $\mathbf{2 5} \%$ & -357 & $32 \%$ \\
\hline $\mathbf{5 0} \%$ & -269 & $247 \%$ \\
\hline $\mathbf{7 5} \%$ & -179 & $551 \%$ \\
\hline $\mathbf{9 0} \%$ & -82 & $1389 \%$ \\
\hline $\mathbf{9 5} \%$ & -42 & $2415 \%$ \\
\hline $\mathbf{9 9} \%$ & -11 & $11302 \%$ \\
\hline
\end{tabular}

[1] Marland, Eric, Domke, Grant, Hoyle, Jason, Marland, Gregg, Bates, Laurel, Helms, Alex, Jones, Benjamin, Kowalczyk, Tamara, Ruseva, Tatyana B., and Szymanski, Celina, "Overview of the Compliance Offset Protocol for U.S. Forest Projects," in Understanding and Analysis: The California Air Resources Board Forest Offset Protocol, 2017, pp. 13-20.

[2] California Air Resources Board, "Compliance Offset Protocol US Forest Projects," 2015. https://www.arb.ca.gov/cc/capandtrade/protocols/usforest/forestprotocol2015.pdf.

[3] Hoover, Coeli M. and Rebain, Stephanie A., "Forest Carbon Estimation Using the Forest Vegetation Simulator: Seven Things You Need to Know," 2011. [Online]. Available: http://www.fs.fed.us/fmsc/fvs/.

[4] Bagdon, Benjamin A., Nguyen, Trung H., Vorster, Anthony, Paustian, Keith, and Field, John L., "A model evaluation framework applied to the Forest Vegetation Simulator (FVS) in Colorado and Wyoming lodgepole pine forests," For. Ecol. Manage., vol. 480, Jan. 2021, doi: 10.1016/j.foreco.2020.118619.

[5] Jones, Dryw A. and O'Hara, Kevin L., “Carbon density in managed coast redwood stands: Implications for forest carbon estimation," Forestry, vol. 85, no. 1, pp. 99-110, Jan. 2012, doi: 10.1093/forestry/cpr063.

[6] Dooner, John and Andreu, Michael G., “Timber Inventory: a primer for landowners,” EDIS, vol. 2020, no. 2, p. 7, Mar. 2020, doi: 10.32473/edis-fr426-2020.

[7] Marino, Bruno D. V., Mincheva, Martina, and Doucett, Aaron, "California air resources board protocol 
invalidates offsets," PeerJ, vol. 7, no. e7606, 2019, doi: https://doi.org/10.7717/peerj.7606.

[8] Marino, Bruno D. V., Truong, Vinh, William Munger, J., and Gyimah, Richard, "Direct measurement forest carbon protocol: A commercial system-of-systems to incentivize forest restoration and management," Peer], vol. 2020, no. 4, p. e8891, Apr. 2020, doi: 10.7717/peerj.8891.

[9] Badgley, Grayson, Freeman, Jeremy, Hamman, Joseph J., Haya, Barbara, Trugman, Anna T., Anderegg, William R. L., and Cullenward, Danny, "Title Systematic over-crediting in California's forest carbon offsets program," bioRxiv, p. 2021.04.28.441870, Apr. 2021, doi: 10.1101/2021.04.28.441870.

[10] Haya, Barbara, Cullenward, Danny, Strong, Aaron L., Grubert, Emily, Heilmayr, Robert, Sivas, Deborah A., and Wara, Michael, "Managing uncertainty in carbon offsets: insights from California's standardized approach," Clim. Policy, vol. 20, no. 9, pp. 1112-1126, Oct. 2020, doi: 10.1080/14693062.2020.1781035.

[11] Hepburn, Cameron, "Carbon Trading: A Review of the Kyoto Mechanisms," Annu. Rev. Environ. Resour., vol. 32, no. 1, pp. 375-393, Nov. 2007, doi: 10.1146/annurev.energy.32.053006.141203.

[12] Zhang, Bin, Lai, Kee-hung, Wang, Bo, and Wang, Zhaohua, "The clean development mechanism and corporate financial performance: Empirical evidence from China," Resour. Conserv. Recycl., vol. 129, pp. 278-289, Feb. 2018, doi: 10.1016/J.RESCONREC.2017.10.004.

[13] Clean Development Mechanism, "A/R Large-scale Consolidated Methodology Afforestation and reforestation of lands except wetlands, Version 2013. https://cdm.unfccc.int/filestorage/T/H/N/THNRJC15IW4K89UBE6DFZYX23OVP0Q/EB75_repan30_ARACM0003_ver02.0.pdf?t=QWh8cWo0b2RzfDDh5qlM_mdDIMQPSsAPeq6Z (accessed Oct. 28, 2020).

[14] Kollmuss, A. and Fussler, J., "Overview of carbon offset programs: Similarities and differences. Partnership for Market Readiness (PMR) Technical Note," Washington, DC, $2015 . \quad$ [Online]. Available: https://www.thepmr.org/system/files/documents/PMR Technical Note 6_Offsets_0.pdf.

[15] Michaelowa, Axel, Shishlov, Igor, Hoch, Stephan, Bofill, Patricio, and Espelage, Aglaja, “Overview and comparison of existing carbon crediting schemes," Zurich, Switzerland, 2019. doi: https://doi.org/10.5167/uzh175378.

[16] Aubinet, Marc, Vesala, Timo, and Papale, Dario, Eddy Covariance: A Practical Guide to Measurement and Data Analysis. Springer Science \& Business Media, 2012.

[17] Chapin, F. S., Woodwell, G. M., Randerson, J. T., Rastetter, E. B., Lovett, G. M., Baldocchi, D. D., Clark, D. a., Harmon, M. E., Schimel, D. S., Valentini, R., Wirth, C., Aber, J. D., Cole, J. J., Goulden, M. L., Harden, J. W., Heimann, M., et al., "Reconciling carbon-cycle concepts, terminology, and methods," Ecosystems, vol. 9, no. 7, pp. 1041-1050, 2006, doi: 10.1007/s10021-005-0105-7.

[18] Baldocchi, Dennis and Penuelas, Josep, "The physics and ecology of mining carbon dioxide from the atmosphere by ecosystems," Glob. Chang. Biol., no. December 2018, pp. 1-7, 2019, doi: 10.1111/gcb.14559.

[19] Pastorello, Gilberto, Trotta, Carlo, Canfora, Eleonora, Chu, Housen, Christianson, Danielle, Cheah, You Wei, Poindexter, Cristina, Chen, Jiquan, Elbashandy, Abdelrahman, Humphrey, Marty, Isaac, Peter, Polidori, Diego, Ribeca, Alessio, van Ingen, Catharine, Zhang, Leiming, Amiro, Brian, et al., "The FLUXNET2015 dataset and the ONEFlux processing pipeline for eddy covariance data," Sci. data, vol. 7, no. 1, p. 225, Jul. 2020, doi: 10.1038/s41597-020-0534-3.

[20] Marino, Bruno D. V., Bautista, Nahuel, and Rousseaux, Brandt, "Howland Forest, ME, USA: Multi-Gas Flux (CO2, CH4, N2O) Social Cost Product Underscores Limited Carbon Proxies," Land, vol. 10, no. 4, p. 436, Apr. 2021, doi: 10.3390/land10040436.

[21] Climate Action Reserve, "Forest Project Protocol Version 3.3," Climate Action Reserve, 2012. http://www.climateactionreserve.org/how/protocols/forest/dev/version-3-3/. 
[22] Winrock International, "THE AMERICAN CARBON REGISTRY STANDARD REQUIREMENTS AND SPECIFICATIONS FOR THE QUANTIFICATION, MONITORING, REPORTING, VERIFICATION, AND REGISTRATION OF PROJECT-BASED GHG EMISSIONS REDUCTIONS AND REMOVALS," 2019. https://americancarbonregistry.org/carbon-accounting/standards-methodologies/american-carbon-registrystandard/acr-standard-v6_final_july-01-2019.pdf (accessed Oct. 28, 2020).

[23] “CDM METHODOLOGY BOOKLET CLEAN DEVELOPMENT MECHANISM,” 2017. Accessed: May 20, 2018. [Online]. Available: https://cdm.unfccc.int/methodologies/documentation/meth_booklet.pdf\#AR_ACM0003.

[24] Shoch, David, Swails, Erin, Hall, Edie Sonne, Belair, Ethan, Griscom, Bronson, and Latta, Greg, "METHODOLOGY FOR IMPROVED FOREST MANAGEMENT," 2020. https://verra.org/wpcontent/uploads/2020/08/FFCP_Methodology_10Aug2020.pdf (accessed Oct. 28, 2020).

[25] Rogelj, Joeri, Den Elzen, Michel, Höhne, Niklas, Fransen, Taryn, Fekete, Hanna, Winkler, Harald, Schaeffer, Roberto, Sha, Fu, Riahi, Keywan, and Meinshausen, Malte, "Paris Agreement climate proposals need a boost to keep warming well below $2{ }^{\circ}{ }^{c}$," Nature, vol. 534, no. 7609. pp. 631-639, 2016, doi: 10.1038/nature18307.

[26] Grassi, Giacomo, House, Jo, Dentener, Frank, Federici, Sandro, den Elzen, Michel, and Penman, Jim, "The key role of forests in meeting climate targets requires science for credible mitigation," Nat. Clim. Chang., vol. 7, no. 3, pp. 220-226, 2017, doi: 10.1038/nclimate3227.

[27] Köhl, Michael, Neupane, Prem Raj, and Mundhenk, Philip, "REDD+ measurement, reporting and verification A cost trap? Implications for financing REDD+MRV costs by result-based payments," Ecol. Econ., vol. 168, pp. 113, Feb. 2020, doi: 10.1016/j.ecolecon.2019.106513.

[28] Reichstein, Markus, Falge, Eva, Baldocchi, Dennis, Papale, Dario, Aubinet, Marc, Berbigier, Paul, Bernhofer, Christian, Buchmann, Nina, Gilmanov, Tagir, Granier, André, Grünwald, Thomas, Havránková, Katka, Ilvesniemi, Hannu, Janous, Dalibor, Knohl, Alexander, Laurila, Tuomas, et al., "On the separation of net ecosystem exchange into assimilation and ecosystem respiration: Review and improved algorithm," Global Change Biology, vol. 11, no. 9. Wiley Online Library, pp. 1424-1439, 2005, doi: 10.1111/j.1365-2486.2005.001002.x.

[29] CARB Air Resources Board, "Offset Project Registries, California Air Resources Board." https://ww2.arb.ca.gov/our-work/programs/compliance-offset-program/offset-project-registries.

[30] Climate Action Reserve, "Climate Action Reserve Project Registry." https://thereserve2.apx.com/myModule/rpt/myrpt.asp?r=111.

[31] Winrock International, “American Carbon Registry Offset Registry," 2020. https://acr2.apx.com/mymodule/mypage.asp (accessed Oct. 19, 2016).

[32] VERRA, “Verified Carbon Standard Registry System," 2020. https://verra.org/project/vcs-program/registrysystem/.

[33] CDM UNFCCC, “CDM Registry." https://cdm.unfccc.int/Registry/index.html.

[34] Marland, Eric, Domke, Grant, Hoyle, Jason, Marland, Gregg, Bates, Laurel, Helms, Alex, Jones, Benjamin, Kowalczyk, Tamara, Ruseva, Tatyana B., and Szymanski, Celina, Understanding and Analysis: The California Air Resources Board Forest Offset Protocol. Springer, 2017.

[35] California Air Resources Board, "ARB offsets Issued," 2018. https://www.arb.ca.gov/cc/capandtrade/offsets/issuance/arb_offset_credit_issuance_table.pdf.

[36] Garcia, Eduardo, AB-398 California Global Warming Solutions Act of 2006: market-based compliance mechanisms: fire prevention fees: sales and use tax manufacturing exemption. USA, 2017.

[37] Cawrse, Dave, Keyser, Chad, Keyser, Tara, Sanchez, Andrew, Smith-Mateja, Erin, and Van Dyck, Mike, "Forest Vegetation Simulator Model Validation Protocols," Fort Collins, CO USDA - For. Serv. For. Manag. Serv. Cent., no. January, pp. 1-10, 2009, Accessed: May 20, 2018. [Online]. Available: 
https://www.fs.fed.us/fmsc/ftp/fvs/docs/steering/FVS_Model_Validation_Protocols.pdf.

[38] Baldocchi, Dennis D., "How eddy covariance flux measurements have contributed to our understanding of Global Change Biology," Glob. Chang. Biol., vol. 26, no. 1, pp. 242-260, Jan. 2019, doi: 10.1111/gcb.14807.

[39] Brailsford, G., "GAW Report No . 206 16th WMO / IAEA Meeting on Carbon Dioxide, Other Greenhouse Gases, and Related Measurement Techniques ( GGMT-2011 )," 2012. https://library.wmo.int/pmb_ged/gaw_206.pdf.

[40] “WMO," "Standards." http://www.wmo.int/pages/governance/policy/tech_regu_en.html.

[41] "FLUXNET." https://fluxnet.ornl.gov/.

[42] "Ameriflux," "Ameriflux." http://ameriflux.lbl.gov/.

[43] "AsiaFlux." http://www.asiaflux.net/ (accessed Oct. 27, 2020).

[44] “European Fluxes Database Cluster." http://www.europe-fluxdata.eu/ (accessed Oct. 27, 2020).

[45] Papale, Dario, Reichstein, Markus, Aubinet, Marc, Canfora, E., Bernhofer, C., Kutsch, W., Longdoz, Bernard, Rambal, Serge, Valentini, R., Vesala, T., and Yakir, D., “Towards a standardized processing of Net Ecosystem Exchange measured with eddy covariance technique: Algorithms and uncertainty estimation," Biogeosciences, vol. 3, no. 4, pp. 571-583, 2006, doi: 10.5194/bg-3-571-2006.

[46] Falge, Eva, Baldocchi, Dennis, Olson, Richard, Anthoni, Peter, Aubinet, Marc, Bernhofer, Christian, Burba, George, Ceulemans, Reinhart, Clement, Robert, Dolman, Han, Granier, André, Gross, Patrick, Grünwald, Thomas, Hollinger, David, Jensen, Niels Otto, Katul, Gabriel, et al., "Gap filling strategies for defensible annual sums of net ecosystem exchange," Agric. For. Meteorol., vol. 107, no. 1, pp. 43-69, 2001, doi: 10.1016/S01681923(00)00225-2.

[47] Wutzler, Thomas, Lucas-Moffat, Antje, Migliavacca, Mirco, Knauer, Jürgen, Sickel, Kerstin, Šigut, Ladislav, Menzer, Olaf, and Reichstein, Markus, "Basic and extensible post-processing of eddy covariance flux data with REddyProc," Biogeosciences, vol. 15, no. 16, pp. 5015-5030, 2018, doi: 10.5194/bg-15-5015-2018.

[48] Finzi, Adrien C., Giasson, Marc André, Barker Plotkin, Audrey A., Aber, John D., Boose, Emery R., Davidson, Eric A., Dietze, Michael C., Ellison, Aaron M., Frey, Serita D., Goldman, Evan, Keenan, Trevor F., Melillo, Jerry M., Munger, J. William, Nadelhoffer, Knute J., Ollinger, Scott V., Orwig, David A., et al., "Carbon budget of the Harvard Forest Long-Term Ecological Research site: pattern, process, and response to global change," Ecol. Monogr., Oct. 2020, doi: 10.1002/ecm.1423.

[49] Bautista, Nahuel, Marino, Bruno D. V., and Munger, J. William, "Science to Commerce: A Commercial-Scale Protocol for Carbon Trading Applied to a 28-Year Record of Forest Carbon Monitoring at the Harvard Forest," Land, vol. 10, no. 2, p. 163, 2021, doi: 10.3390/land10020163.

[50] Woodbury, P., Smith, J., and Heath, L., "Carbon sequestration in the U.S. forest sector from 1990 to 2010," For. Ecol. Manage., vol. 241, no. 1-3, pp. 14-27, Mar. 2007, doi: 10.1016/j.foreco.2006.12.008.

[51] Richardson, Andrew D., Hollinger, David Y., Shoemaker, Julie K., Hughes, Holly, Savage, Kathleen, and Davidson, Eric A., "Six years of ecosystem-atmosphere greenhouse gas fluxes measured in a sub-boreal forest," Sci. Data, vol. 6, no. 1, pp. 1-15, Dec. 2019, doi: 10.1038/s41597-019-0119-1.

[52] Fitzgerald, Colm, "The Forestry Investment Total Return (FITR) Index," J. Altern. Investments, vol. 23, no. 4, pp. 131-150, Mar. 2021, doi: 10.3905/jai.2021.1.125.

[53] Bond-Lamberty, Ben, Bailey, Vanessa L., Chen, Min, Gough, Christopher M., and Vargas, Rodrigo, "Globally rising soil heterotrophic respiration over recent decades," Nature, vol. 560, no. 7716, pp. 80-83, 2018, doi: 10.1038/s41586-018-0358-x.

[54] Anderson, Christa M., Field, Christopher B., and Mach, Katharine J., "Forest offsets partner climate-change mitigation with conservation," Front. Ecol. Environ., vol. 15, no. 7, pp. 359-365, Sep. 2017, doi: 10.1002/fee.1515.

[55] Curtis, P., Hanson, P., Bolstad, P., Barford, C., Randolph, J., Schmid, H., and Wilson, K., “Biometric and eddy- 
covariance based estimates of annual carbon storage in five eastern North American deciduous forests," Agric. For. Meteorol., vol. 113, no. 1-4, pp. 3-19, Dec. 2002, doi: 10.1016/S0168-1923(02)00099-0.

[56] Campioli, M., Malhi, Y., Vicca, S., Luyssaert, S., Papale, D., Peñuelas, J., Reichstein, M., Migliavacca, M., Arain, M. A., and Janssens, I. A., "Evaluating the convergence between eddy-covariance and biometric methods for assessing carbon budgets of forests," Nat. Commun., vol. 7, 2016, doi: 10.1038/ncomms13717.

[57] Ouimette, Andrew P., Ollinger, Scott V., Richardson, Andrew D., Hollinger, David Y., Keenan, Trevor F., Lepine, Lucie C., and Vadeboncoeur, Matthew A., "Carbon fluxes and interannual drivers in a temperate forest ecosystem assessed through comparison of top-down and bottom-up approaches," Agric. For. Meteorol., vol. 256257, pp. 420-430, 2018, doi: 10.1016/j.agrformet.2018.03.017.

[58] Vestin, Patrik, Mölder, Meelis, Kljun, Natascha, Cai, Zhanzhang, Hasan, Abdulghani, Holst, Jutta, Klemedtsson, Leif, and Lindroth, Anders, "Impacts of clear-cutting of a boreal forest on carbon dioxide, methane and nitrous oxide fluxes," Forests, vol. 11, no. 9, p. 961, Sep. 2020, doi: 10.3390/f11090961.

[59] Machacova, Katerina, Borak, Libor, Agyei, Thomas, Schindler, Thomas, Soosaar, Kaido, Mander, Ülo, and AhPeng, Claudine, "Trees as net sinks for methane (CH4) and nitrous oxide (N2O) in the lowland tropical rain forest on volcanic Réunion Island," New Phytol., vol. 229, no. 4, pp. 1983-1994, 2021, doi: 10.1111/nph.17002.

[60] Forsythe, Jeremy D., O'halloran, Thomas L., and Kline, Michael A., "An eddy covariance mesonet for measuring greenhouse gas fluxes in coastal south carolina," Data, vol. 5, no. 4, pp. 1-20, Oct. 2020, doi: 10.3390/data5040097.

[61] Reitz, O., Graf, A., Schmidt, M., Ketzler, G., and Leuchner, M., “Upscaling Net Ecosystem Exchange over Heterogeneous Landscapes with Machine Learning," J. Geophys. Res. Biogeosciences, Dec. 2020, doi: 10.1029/2020jg005814.

[62] Haya, Barbara, "POLICY BRIEF: The California Air Resources Board's U.S. Forest offset protocol underestimates leakage," Berkeley, $\quad$ CA, $2019 . \quad$ [Online]. Available: https://gspp.berkeley.edu/assets/uploads/research/pdf/Policy_Brief-US_Forest_Projects-Leakage-Haya_2.pdf.

[63] California Air Resources Board, "California Air Resources Board Offset Credit Regulatory Conformance and Invalidation Guidance," 2015. Accessed: May 25, 2018. [Online]. Available: https://www.arb.ca.gov/cc/capandtrade/offsets/arboc_guide_regul_conform_invalidation.pdf.

[64] Baldocchi, Dennis, Chu, Housen, and Reichstein, Markus, "Inter-annual variability of net and gross ecosystem carbon fluxes: A review," Agric. For. Meteorol., vol. 249, pp. 520-533, Feb. 2018, doi: 10.1016/j.agrformet.2017.05.015.

[65] Busby, Gwenlyn M., Binkley, Clark S., and Chudy, Rafal P., “Constructing optimal global timberland investment portfolios," For. Policy Econ., vol. 111, Feb. 2020, doi: 10.1016/j.forpol.2019.102083.

[66] Giasson, M. A., Ellison, A. M., Bowden, R. D., Crill, P. M., Davidson, E. A., Drake, J. E., Frey, S. D., Hadley, J. L., Lavine, M., Melillo, J. M., Munger, J. W., Nadelhoffer, K. J., Nicoll, L., Ollinger, S. V., Savage, K. E., Steudler, P. A., et al., "Soil respiration in a northeastern US temperate forest: A 22-year synthesis," Ecosphere, vol. 4, no. 11, 2013, doi: 10.1890/ES13.00183.1.

[67] Cunha-e-Sá, Maria A., Rosa, Renato, and Costa-Duarte, Clara, "Natural carbon capture and storage (NCCS): Forests, land use and carbon accounting," Resour. Energy Econ., vol. 35, no. 2, pp. 148-170, May 2013, doi: 10.1016/j.reseneeco.2012.12.003.

[68] Rockström, Johan, Steffen, Will, Noone, Kevin, Persson, Åsa, Chapin, F. Stuart, Lambin, Eric, Lenton, Timothy M., Scheffer, Marten, Folke, Carl, Schellnhuber, Hans Joachim, Nykvist, Björn, de Wit, Cynthia A., Hughes, Terry, van der Leeuw, Sander, Rodhe, Henning, Sörlin, Sverker, et al., "Planetary boundaries: Exploring the safe operating space for humanity," Ecol. Soc., vol. 14, no. 2, p. 32, 2009, doi: 10.5751/ES-03180-140232.

[69] Chazdon, Robin and Brancalion, Pedro, "Restoring forests as a means to many ends," Science (80-. )., vol. 365, no. 
6448, pp. 24-25, 2019, doi: 10.1126/science.aax9539.

[70] Bastin, Jean-Francois, “The global tree restoration potential," Science (80-. )., vol. 365, no. 6448, pp. 76-79, Jul. 2019, doi: 10.1126/science.aax0848.

[71] Funk, Jason M., Aguilar-Amuchastegui, Naikoa, Baldwin-Cantello, William, Busch, Jonah, Chuvasov, Evgeny, Evans, Tom, Griffin, Bryna, Harris, Nancy, Ferreira, Mariana Napolitano, Petersen, Karen, Phillips, Oliver, Soares, Muri G., and van der Hoff, Richard J. A., "Securing the climate benefits of stable forests," Clim. Policy, vol. 19, no. 7, pp. 845-860, Aug. 2019, doi: 10.1080/14693062.2019.1598838.

[72] Peters, Glen P., Andrew, Robbie M., Canadell, Josep G., Fuss, Sabine, Jackson, Robert B., Korsbakken, Jan Ivar, Le Quéré, Corinne, and Nakicenovic, Nebojsa, “Key indicators to track current progress and future ambition of the Paris Agreement," Nat. Clim. Chang., vol. 7, no. 2, pp. 118-122, 2017, doi: 10.1038/nclimate3202.

[73] Townsend, Justine, Moola, Faisal, and Craig, Mary-Kate, "Indigenous Peoples are critical to the success of nature-based solutions to climate change," FACETS, vol. 5, no. 1, pp. 551-556, Jan. 2020, doi: 10.1139/facets-20190058.

[74] Metzger, Stefan, Ayres, Edward, Durden, David, Florian, Christopher, Lee, Robert, Lunch, Claire, Luo, Hongyan, Pingintha-Durden, Natchaya, Roberti, Joshua A., Sanclements, Michael, Sturtevant, Cove, Xu, Ke, and Zulueta, Rommel C., "FROM NEON FIELD SITES TO DATA PORTAL: A Community Resource for Surface-Atmosphere Research Comes Online," Bull. Am. Meteorol. Soc., Oct. 2019, doi: 10.1175/bams-d-17-0307.1.

[75] Novick, K. A., Biederman, J. A., Desai, A. R., Litvak, M. E., Moore, D. J. P., Scott, R. L., and Torn, M. S., “The AmeriFlux network: A coalition of the willing," Agric. For. Meteorol., vol. 249, pp. 444-456, Feb. 2018, doi: 10.1016/J.AGRFORMET.2017.10.009.

[76] Climate Action Reserve, "Comparison of California ARB Compliance Offset Protocol to Climate Action Reserve Voluntary Offset Project Protocol Version 3.2," 2017. http://www.climateactionreserve.org/how/californiacompliance-projects/compliance-offset-program-documents/.

[77] World Bank, "State and Trends of Carbon Pricing 2020," 2020. https://openknowledge.worldbank.org/handle/10986/33809.

[78] Pastorello, Gilberto, Agarwal, Deb, Papale, Dario, Samak, Taghrid, Trotta, Carlo, Ribeca, Alessio, Poindexter, Cristina, Faybishenko, Boris, Gunter, Dan, Hollowgrass, Rachel, and Canfora, Eleonora, “Observational data patterns for time series data quality assessment," in Proceedings - 2014 IEEE 10th International Conference on eScience, eScience 2014, Dec. 2014, vol. 1, pp. 271-278, doi: 10.1109/eScience.2014.45.

[79] California Air Resources Board, "California Air Resources Board Offset Credit Regulatory Conformance and Invalidation Guidance," $2015 . \quad$ [Online]. Available: https://www.arb.ca.gov/cc/capandtrade/offsets/arboc_guide_regul_conform_invalidation.pdf.

[80] Climate Action "Reserve Offset Program Manual," 2020. http://www.climateactionreserve.org/how/program/program-manual/.

[81] California Air Resources Board, “Article 5: CALIFORNIA CAP ON GREENHOUSE GAS EMISSIONS AND MARKET-BASED COMPLIANCE MECHANISMS," 2011. Accessed: Oct. 28, 2020. [Online]. Available: https://ww2.arb.ca.gov/sites/default/files/classic//cc/capandtrade/finalregorder.pdfpdf.

[82] Gough, C. M., Vogel, C. S., Schmid, H. P., Su, H. B., and Curtis, P. S., “Multi-year convergence of biometric and meteorological estimates of forest carbon storage," Agric. For. Meteorol., vol. 148, no. 2, pp. 158-170, 2008, doi: 10.1016/j.agrformet.2007.08.004.

[83] "Compliance Offset Protocol U.S. Forest Offset http://www.arb.ca.gov/cc/capandtrade/protocols/usforest/usforestprojects_2015.htm (accessed Nov. 10, 2015). 